\title{
A cascade Suzuki-Miyaura/Diels-Alder protocol: Exploring the bifunctional utility of vinyl Bpin
}

\author{
David L. Cain ${ }^{a}$ \\ Calum McLaughlin ${ }^{b}$ \\ John J. Molloy \\ Cameron Carpenter-Warren ${ }^{a}$ \\ Niall A. Anderson ${ }^{c}$ \\ Allan J. B. Watson ${ }^{\text {a* }}$ \\ a EaStCHEM, School of Chemistry, University of St Andrews, \\ North Haugh, St Andrews, KY16 9ST, UK. \\ ${ }^{b}$ WestCHEM, Department of Pure and Applied Chemistry, \\ University of Strathclyde, 295 Cathedral Street, Glasgow, G1 \\ $1 \mathrm{XL}, \mathrm{UK}$ \\ ' GlaxoSmithKline, Medicines Research Centre, Gunnels Wood \\ Road Stevenage, Hertfordshire, SG1 2NY, UK.

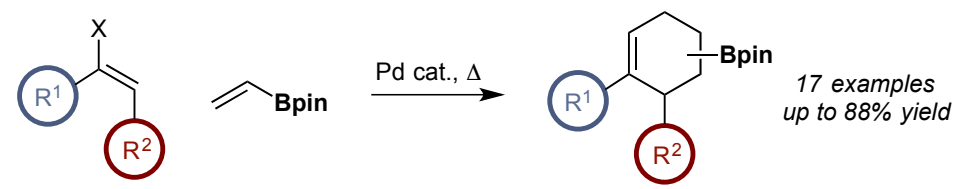

- Vinyl Bpin as a bifunctional reagent

- Tandem Suzuki-Miyaura/Diels-Alder reaction

- Rapid access to borylated cyclohexenes

\section{Received:
Accepted:
Published online:
DOl:}

Abstract Cascade reactions are an important strategy in reaction design, allowing streamlining of chemical synthesis. Here we report a cascade Suzuki-Miyaura/Diels-Alder reaction, employing vinyl Bpin as a bifunctional reagent in two distinct roles: as an organoboron nucleophile for crosscoupling and as a Diels-Alder dienophile. Merging these two reactions enables a rapid and operationally simple synthesis of functionalized carbocycles in good yield. The effect of the organoboron subtype on DielsAlder regioselectivity was investigated and post-synthetic modifications were carried out on a model substrate. The potential for a complementary Heck/Diels-Alder process was also assessed.

Key words Bpin, cascade, cross-coupling, Diels-Alder, Suzuki-Miyaura

Cascade methodologies are recognized as an enabling approach to chemical synthesis. ${ }^{1-4}$ The modularity with which complex molecules can be created from embedding downstream reactivity into small precursors is an appealing strategy for synthetic chemists, allowing the use of highly reactive, non-isolable intermediates, reducing step count, and leading to overall improvements in chemical efficiency.

The Diels-Alder (DA) reaction is one of the most widely explored reactions within cascade sequences. ${ }^{1-4}$ This popularity stems from variety of methods to prepare dienes, in combination with the ability to effectively generate stereochemically-enriched 6-membered rings with relative ease. The diene component of the DA reaction can often be challenging to handle since particular dienes are prone to rapid decomposition or polymerization upon isolation..$^{5}$ As a result, considerable research has been focused on the generation and in situ applications of specific dienes. ${ }^{6-15}$

Cross-coupling reactions are effective methods for the preparation of dienes for in situ DA reactions.13-15 For example, Padwa reported a cascade Stille/intramolecular DA to form complex tetracyclic fused ring systems (Scheme 1a). ${ }^{16}$ Lee employed a cascade DA/cross-coupling protocol, generating an organoindium reagent in situ, to enable a subsequent Pdcatalyzed cross-coupling (Scheme 1b). ${ }^{17}$ Welker reported a three-component tandem Suzuki-Miyaura/DA cascade involving an initial cycloaddition between a borylated diene and electron-deficient dienophile followed by a subsequent cross-coupling with an aryl iodide (Scheme 1c). ${ }^{18}$ In all previously reported methods the DA is performed with a highly activated, electron-deficient dienophile. We recently disclosed a tandem cross-coupling/DA reaction, to generate molecular complexity. ${ }^{19}$ Again, these reactions required highly activated dienophiles to promote reactivity.

Here we explore the utility of vinyl Bpin as both cross-coupling nucleophile and dienophile for the cascade synthesis of borylated carbocycles (Scheme 1d).
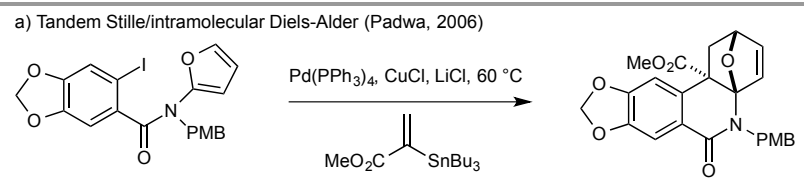

b) Tandem Diels-Alder/cross-coupling reaction (Lee, 2010)
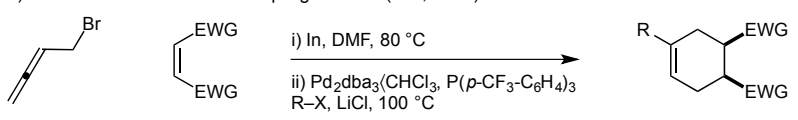

c) Tandem Diels-Alder/cross-coupling protocol (Welker, 2012)

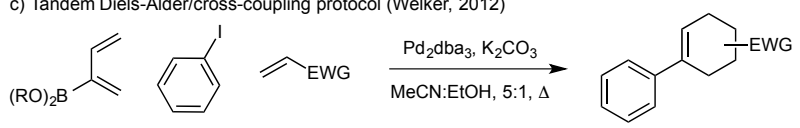

d) This work: Exploring the bifunctional utility of vinyl Bpin

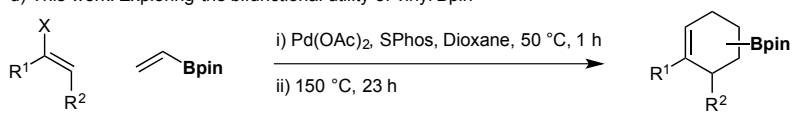

Scheme 1 Cross-coupling/DA in cascade methodologies. DMF $=N, N$ dimethylformamide; $E W G$ = electron withdrawing group; pin = pinacolato; $\mathrm{PMB}=$ para-methoxybenzyl. 
Table 1 Optimization of SM/DA cascade reaction

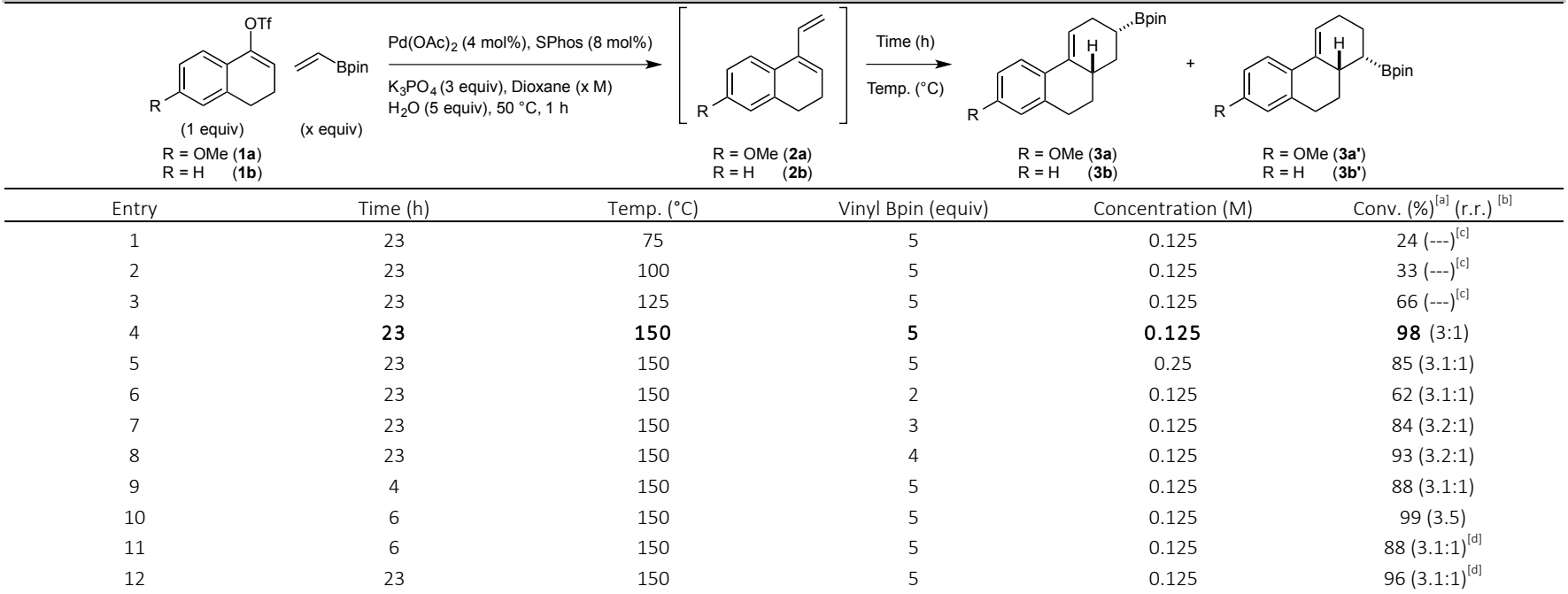

${ }^{a}$ Conversion determined by ${ }^{1} \mathrm{H}$ NMR using an internal standard. ${ }^{b}$ r.r. = regioisomeric ratio of $3 a: 3 a{ }^{\prime}$ or $3 b: 3 b^{\prime}$. Determined by ${ }^{1} \mathrm{H}$ NMR after oxidation. ${ }^{c}$ Unable to be determined due to impurity profile. ${ }^{d}$ Reactions using $1 \mathrm{~b}$.

While vinyl Bpin is a competent cross-coupling nucleophile, its utility as a dienophile is underdeveloped. ${ }^{19,20}$ However, a crosscoupling/Diels-Alder cascade utilizing vinyl Bpin as both nucleophile and dienophile would construct borylated cyclohexenes, capable of an array of further transformations.

We initiated the optimization study (Table 1) using triflate 1a with excess vinyl BPin. Employing conditions previously established in our group, ${ }^{21-25}$ the Suzuki-Miyaura event proceeded rapidly and quantitatively, delivering Dane's diene (2a) as an intermediate. ${ }^{26,27}$ We believed thermal promotion would enable cyclization and a temperature screen indicated that a minimum of $150{ }^{\circ} \mathrm{C}$ (entries 1-4) was necessary to drive the DA reaction to completion. 5 equivalents of vinyl BPin were required to overcome organoboron degradation and offset a competing homo Diels-Alder consuming diene intermediate 2a (entries 6-8). A time study indicated that the reaction was complete in $6 \mathrm{~h}$ (entries 9 and 10). Given the electron-rich, reactive nature of the intermediate diene $\mathbf{2 a}$, we were concerned that these reaction conditions would not be broadly transferrable. A control experiment using des-methoxy triflate $\mathbf{1 b}$, via diene $\mathbf{2 b}$, indicated that longer reactions times would potentially be necessary for less electron-rich substrates (entries 11 and 12).

The scope of the reaction was subsequently investigated (Scheme 2). All substrates were isolated as the corresponding alcohol to aid characterization and separation of the regioisomers generated from the cycloaddition. The tetralonederived scaffolds (4a-4g) displayed good yields in all examples, with both electron-donating (4a, $\mathbf{4 d}$, and $\mathbf{4 e}$ ) and electronwithdrawing groups (4f) tolerated, in addition to a chromane example (4g). The position and nature of the substituent on the aromatic ring had little effect on the regioselectivity of the cycloaddition, with a moderate (ca. 3:1) ratio of regioisomers observed throughout. However, a single diastereomer was produced, which following X-ray crystallographic analysis confirmed an endo Diels-Alder adduct (vide infra).

Use of styrenyl and alkenyl electrophiles (4h-4q) allowed the formation of cyclohexenyl products (Scheme 2). Homo DielsAlder was found to be significantly more problematic in these cases. However, this could be circumvented using 7 equivalents of vinyl Bpin to deliver a range of products in good yield and with comparable levels of regiochemical control.

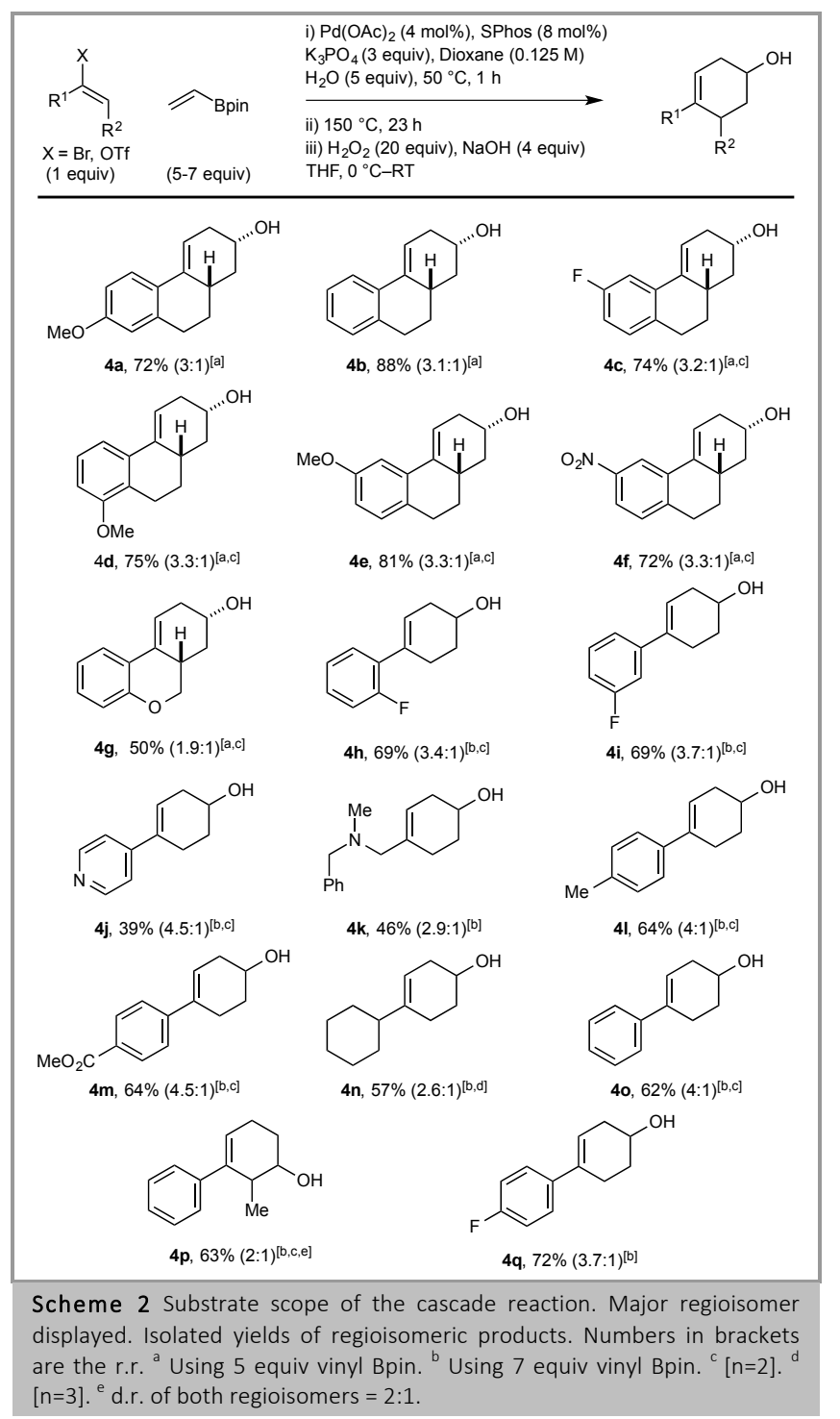


Lastly, use of $\beta$-methyl styrene resulted in the formation of the product $\mathbf{4 p}$ in moderate yield. Interestingly, a change in regioselectivity was observed with this substrate, now favoring what was the minor regioisomer for all previous examples.

Based on the moderate regioselectivity observed throughout as well as the reversal of regioselectivity in example $\mathbf{4 p}$, we were interested to assess what, if any, impact the nature of the organoboron substituent had on the regioselectivity of the cycloaddition (Table 2).

Table 2 Diels-Alder regioselectivity: Variation of vinyl boron species.

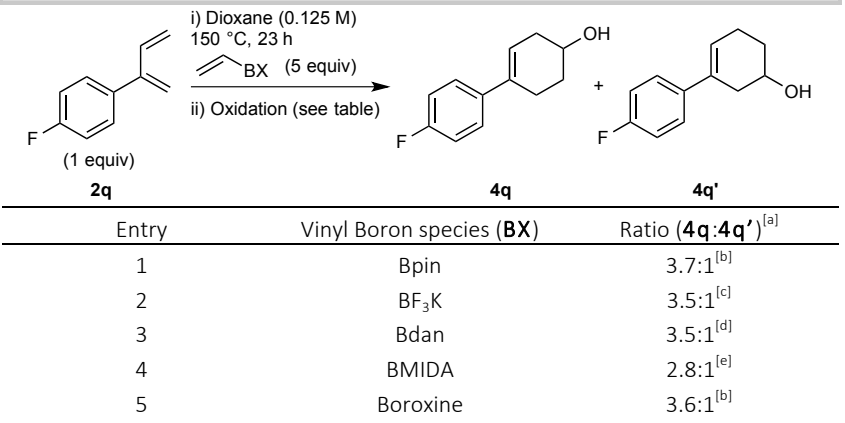

${ }^{a}$ Determined after oxidation to the corresponding alcohol. ${ }^{b}$ Oxidation conditions: $\mathrm{H}_{2} \mathrm{O}_{2}$ (20 equiv), $2 \mathrm{M} \mathrm{NaOH}$ (4 equiv), THF, $0{ }^{\circ} \mathrm{C}-\mathrm{RT}, 1 \mathrm{~h} .{ }^{\mathrm{c}}$ Oxidation conditions: Oxone ${ }^{\oplus}$ (1.1 equiv), acetone $/ \mathrm{H}_{2} \mathrm{O}$ (1:1), $\mathrm{RT}, 2 \mathrm{~h} .{ }^{\mathrm{d}}$ (i) $2 \mathrm{M} \mathrm{HCl}$ (6 equiv), THF, $\mathrm{RT}, 23$ h; (ii) $\mathrm{H}_{2} \mathrm{O}_{2}$ (20 equiv), $2 \mathrm{M} \mathrm{NaOH}$ (4 equiv), THF, $0{ }^{\circ} \mathrm{C}-\mathrm{RT}$, 1 h. ${ }^{\mathrm{e}}$ (i) $\mathrm{K}_{3} \mathrm{PO}_{4}$ (3 equiv), $\mathrm{H}_{2} \mathrm{O}$ (5 equiv), $\mathrm{CPME}, 80{ }^{\circ} \mathrm{C}, 10 \mathrm{~min}$; (ii) Oxone ${ }^{\circledR}$ (2.5 equiv), $\mathrm{CPME} / \mathrm{H}_{2} \mathrm{O}$ (4:1), 70 ${ }^{\circ} \mathrm{C}, 1 \mathrm{~h}$. dan = 1,8-diaminonaphthalenate; $\mathrm{MIDA}=\mathrm{N}$-methyliminodiacetate; pin = pinacolato.

Under the aqueous basic conditions used for the initial SuzukiMiyaura cross-coupling of the tandem process the vinyl BPin could conceivably exist as its boronate derivative, ${ }^{28}$ which exhibits significantly different electronic properties to the parent neutral boronic ester. Since altering the electronics of the dienophile may have a direct influence on the regioselectivity of the cycloaddition, we assessed several different organoboron species (Bpin, BMIDA, boroxine, $\mathrm{BF}_{3} \mathrm{~K}$, BDAN) to determine any influence on regioselectivity (Table 3). However, no noticeable trends were observed, with all reactions producing a similar regioisomeric ratio. However, the cycloaddition requires significant thermal promotion and it is possible that these observations could be explained by the high temperatures required for reactivity overriding any potentially subtler electronically-induced kinetic effects.

In order to demonstrate potential synthetic application of this method, we carried out post-synthetic modifications of a benchmark substrate (4a; major regioisomer). Dihydroxylation, alkene migration, hydrogenation, oxidation, acylation, and alcohol protection were all shown to be feasible, giving compounds 5a-5f and illustrating the potential of diversification capabilities. Compound $\mathbf{5 e}$ was characterized by X-ray diffraction, confirming relative stereochemistry and providing evidence that the cycloaddition proceeds via the endo transition state.

Lastly, we explored the feasibility of performing a Heck/DA cascade reaction using vinyl Bpin (Scheme 4a), given the recent successful methodology implementing a variety of dienophiles, ${ }^{19}$ as this would provide expedient access to vicinyl Bpin systems. Initial efforts in performing the reaction in a onepot process proved unsuccessful; as a result, a step-wise approach was adopted for proof of concept. The Bpin diene intermediate (2d) was successfully isolated, albeit in low yield (Scheme 2b): this reaction delivered complex mixtures of products, likely via homo-Diels-Alder as well as protodeboronation. Despite our best efforts, and our acquired knowledge on this DA reaction, we were unable to obtain the DA adduct (5a) upon exposing the diene (2d) to excess vinyl Bpin at elevated temperatures, with the reaction yielding a complex mixture of unknown products, based on the noted poor stability/high reactivity of intermediate $\mathbf{2 d}$ and exacerbated by the requirement for high temperatures.

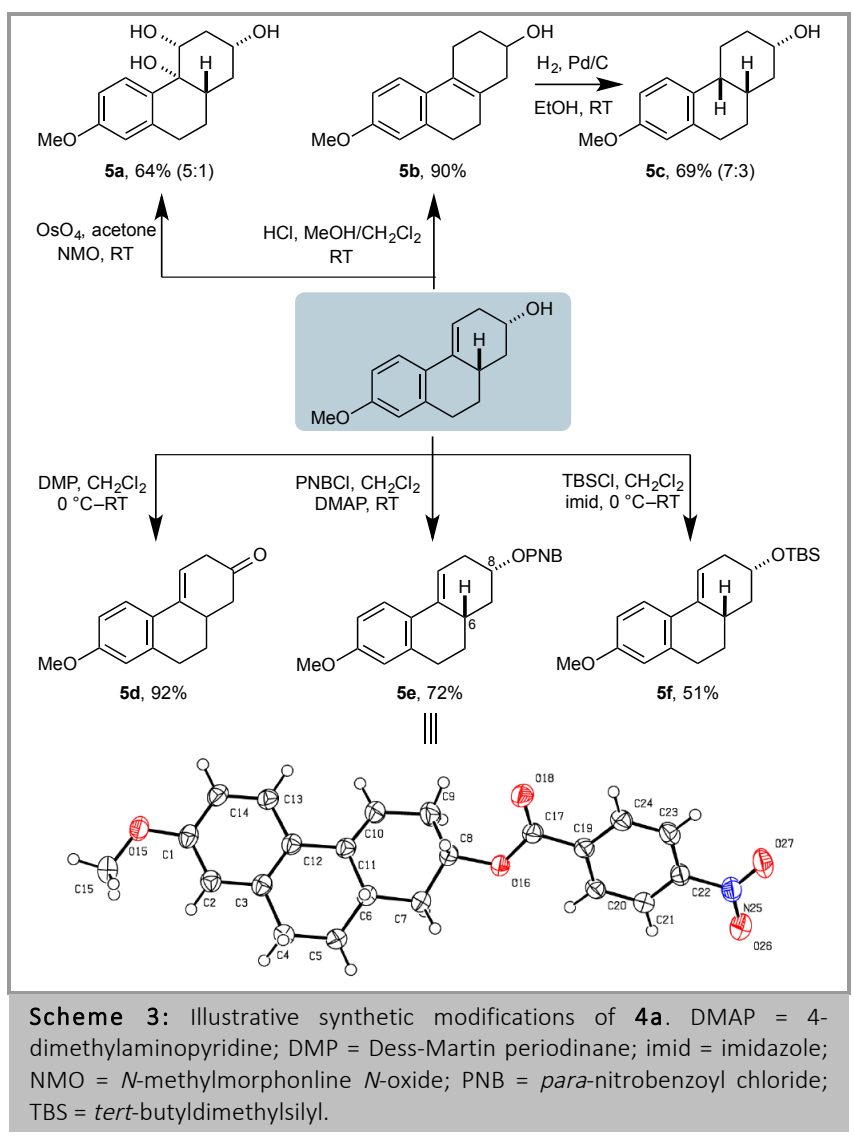

a) Approach to vicinal Bpin products via Heck/Diels-Alder using vinyl Bpin

b) Attempts towards the sequential process

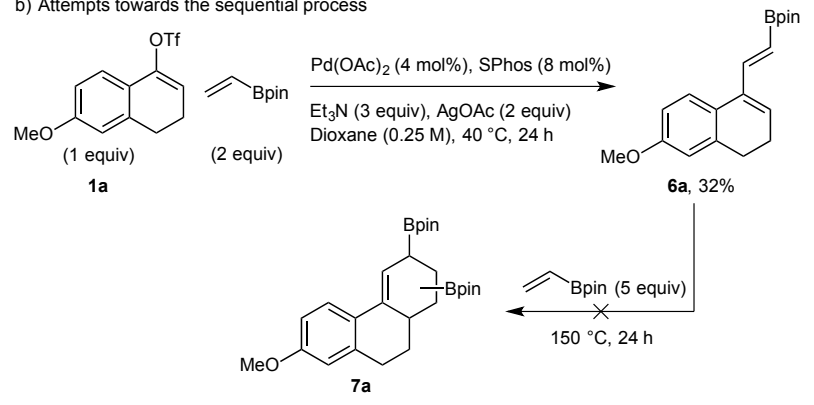

Scheme 4: a) Proposed one-pot cascade Heck/DA reaction; b) stepwise approach to elucidating feasibility of reaction.

In summary, we have developed a cascade SuzukiMiyaura/Diels-Alder protocol enabling expedient access to 
borylated carbogenic frameworks, exploiting the unique reactivity of vinyl Bpin as both cross-coupling partner and dienophile. The process tolerates a variety of functional groups, producing cycloadducts in moderate to good yields and with moderate regioselectivity. The effect of the organoboron substituent on the Diels-Alder regioselectivity was assessed and found to have little impact on the outcome of the process, suggesting the thermal activation required erodes any

\section{Funding Information}

Industrial CASE studentship awarded from EPSRC and GlaxoSmithKline.

\section{Acknowledgment}

We thank the EPSRC, GlaxoSmithKline, and the University of St Andrews for studentship funding (DLC), and the University of St Andrews and the EPSRC UK National Mass Spectrometry Facility at Swansea University for analyses.

\section{Supporting Information}

Yes.

\section{Primary Data}

No.

\section{References and Notes}

(1) Tietze, L. F. Chem. Rev. 1996, 96, 115.

(2) Tietze, L. F.; Lieb, M. E. Curr. Opin. Chem. Biol. 1998, 2, 363.

(3) Nicolaou, K. C.; Edmonds, D. J.; Bulger, P. G. Angew. Chem. Int. Ed. 2006, 45, 7134 .

(4) Winkler, J. D. Chem. Rev. 1996, 96, 167.

(5) Bodwell, G. J.; Pi, Z. Tetrahedron Lett. 1997, 38, 309-312.

(6) Linder, M.; Johansson, A. J.; Manta, B.; Olsson, P.; Brinck, T. Chem. Commun. 2012, 48, 5665.

(7) Ohkita, M.; Kawai, H.; Tsuji, T. J. Chem. Soc., Perkin Trans. 1 2002, 12,366 .

(8) Zhang, L.; Malinakova, H. C. J. Org. Chem. 2007, 72, 1484.

(9) Mario, K.; de Meijere, A. Eur. J. Org. Chem. 2005, 2259.

(10) Guo, T.; Jiang, Q.; Huang, F.; Chen, J.; Yu, Z. Org. Chem. Front. 2014, $1,707$.

(11) Yoshioka, S.; Aoyama, H.; Fujioka, H.; Arisawa, M. J. Org. Chem. 2018, 83, 6599-6606.

(12) Padwa, A.; Gareau, Y.; Harrison, B.; Rodriguez, A. J. Org. Chem. 1992, 57, 3540-3545.

(13) Baris, Y.; Nataša, V.; Mathias, N.; de Meijere, A. Eur. J. Org. Chem. 2007, 4081.

(14) de Meijere, A.; von Zezschwitz, P.; Bräse, S. Acc. Chem. Res. 2005, 38,413 .

(15) Jeges, G.; Skoda-Földes, R.; Kollár, L.; Horváth, J.; Tuba, Z Tetrahedron. 1998, 54, 6767.

(16) Zhang, H.; Padwa, A. Org. Lett. 2006, 8, 247.

(17) Mo, J.; Kim, S. H.; Lee, P. H. Org. Lett. 2010, 12, 424.

(18) Wang, L.; Welker, M. E. J. Org. Chem. 2012, 77, 8280.

(19) Molloy, J. J.; Seath, C. P.; West, M. J.; McLaughlin, C.; Fazakerley, N. J.; Kennedy, A. R.; Nelson, D. J.; Watson, A. J. B. J. Am. Chem. Soc. 2018 $140,126$.

(20) Hilt, G.; Bolze, P. Synthesis 2005, 2091.

(21) Fyfe, J. W. B.; Fazakerley, N. J.; Watson, A. J. B. Angew. Chem. Int. Ed. 2017, 56, 1249.

(22) Seath, C. P.; Fyfe, J. W. B.; Molloy, J. J.; Watson, A. J. B. Angew. Chem. Int. Ed. 2015, 54, 9976. potential stereoelectronically-induced regioselectivity. In addition, a set of derivitization reactions was carried out to demonstrate synthetic versatility of these building blocks as intermediates. Finally the possibility of a cascade Heck/DA reaction was investigated through a stepwise approach, however, the reaction could not be driven to the desired product.

(23) Fyfe, J. W. B.; Seath, C. P.; Watson, A. J. B. Angew. Chem. Int. Ed. 2014, 53, 12077.

(24) Molloy, J. J.; Law, R. P.; Fyfe, J. W. B.; Seath, C. P.; Hirst, D. J.; Watson, A. J. B. Org. Biomol. Chem. 2015, 13, 3093.

(25) Wilson, K. L.; Murray, J.; Jamieson, C.; Watson, A. J. B. Synlett 2018 , 14,650 .

(26) Dane, E.; Höss, O.; Bindseil, A. W.; Schmitt, J. Justus Liebigs Ann. Chem. 1937, 532, 39.

(27) Weimar, M.; Dürner, G.; Bats, J. W.; Göbel, M. W. J. Org. Chem. 2010, 75, 2718.

(28) Molloy, J. J.; Clohessy, T. A.; Irving, C.; Anderson, N. A.; Lloyd-Jones, G. C.; Watson, A. J. B. Chem. Sci. 2017, 8, 1551.

(29) General Experimental Procedure for the Tandem SuzukiMiyaura/Diels-Alder reaction. $\mathrm{Pd}(\mathrm{OAc})_{2}(4 \mathrm{~mol} \%)$, SPhos (8 mol\%), vinyl (pseudo)halide (1 equiv), vinyl Bpin (5-7 equiv), and $\mathrm{K}_{3} \mathrm{PO}_{4}$ (3 equiv) were weighed into an oven dried microwave vial. The reaction vessel was then capped and purged with $\mathrm{N}_{2}$ before the addition of 1,4-dioxane $(0.125 \mathrm{M})$ and $\mathrm{H}_{2} \mathrm{O}$ (5 equiv). The reaction mixture was heated at $50{ }^{\circ} \mathrm{C}$ with stirring. After $1 \mathrm{~h}$ the temperature was increased to $150{ }^{\circ} \mathrm{C}$ and the reaction mixture was stirred for $23 \mathrm{~h}$. The reaction mixture was allowed to cool to room temperature, vented, and de-capped. The reaction mixture was diluted with EtOAc $(20 \mathrm{~mL})$ and passed through a layer of celite, eluting with EtOAc. The filtrate was concentrated under reduced pressure. THF $(0.25 \mathrm{M})$ was added to the crude residue and the solution was cooled to $0{ }^{\circ} \mathrm{C}$ before the addition of $\mathrm{H}_{2} \mathrm{O}_{2}(30 \% \mathrm{w} / \mathrm{v}$, 20 equiv) and $2 \mathrm{M} \mathrm{NaOH}$ (4 equiv) sequentially. After $5 \mathrm{~min}$ the reaction mixture was allowed to warm to room temperature and was stirred for $1 \mathrm{~h}$. The mixture was quenched with $\mathrm{Na}_{2} \mathrm{~S}_{2} \mathrm{O}_{3}$ at $0{ }^{\circ} \mathrm{C}$ until effervescence ceases and diluted with sat. aq. $\mathrm{NH}_{4} \mathrm{Cl}$. The organics were extracted with EtOAc, washed with brine, dried over $\mathrm{Na}_{2} \mathrm{SO}_{4}$, filtered, and concentrated under reduced pressure. The crude residue was purified by column chromatography to afford the desired products.

Compound 4a. Prepared according to General Procedure using 6methoxy-3,4-dihydronaphthalen-1-yl trifluoromethanesulfonate (77.0 mg, $0.25 \mathrm{mmol}, 1$ equiv), $\mathrm{Pd}(\mathrm{OAc})_{2}(2.2 \mathrm{mg}, 0.01 \mathrm{mmol}, 4$ mol\%), SPhos (8.2 mg, $0.02 \mathrm{mmol}, 8 \mathrm{~mol} \%)$, vinyl Bpin (192 mg, 1.25 mmol, 5 equiv), $\mathrm{K}_{3} \mathrm{PO}_{4}(159 \mathrm{mg}, 0.75 \mathrm{mmol}, 3$ equiv), $1,4-$ dioxane ( $2 \mathrm{~mL}, 0.125 \mathrm{M})$ and $\mathrm{H}_{2} \mathrm{O}(22.5 \mu \mathrm{L}, 1.25 \mathrm{mmol}, 5$ equiv), then aqueous $\mathrm{H}_{2} \mathrm{O}_{2}(30 \% \mathrm{w} / \mathrm{v}, 500 \mu \mathrm{L}, 5 \mathrm{mmol}, 20$ equiv), $2 \mathrm{M}$ $\mathrm{NaOH}(500 \mu \mathrm{L}, 1 \mathrm{mmol}, 4$ equiv) and THF ( $1 \mathrm{~mL})$. After the reaction was complete, the reaction mixture was subjected to the purification method outlined in the General Procedure (silica gel, $0-60 \%$ EtOAc in petroleum ether $\left.40-60^{\circ}\right)$ to afford the desired mixture of products as a yellow oil $(41.3 \mathrm{mg}, 72 \%, 3: 1 \mathrm{r.r}$.). The major regioisomer was separated by column chromatography (c.a. 95\% purity). Data for the major regioisomer: $v_{\max }$ (film): 3364 (br), $2914,2847,2830,1605,1493,1456,1279,1253,1231,1034 \mathrm{~cm}$ 1. ${ }^{1} \mathrm{H}$ NMR (400 MHz, $\left.\mathrm{CDCl}_{3}\right): \delta 7.51(\mathrm{dd}, J=8.8,6.0 \mathrm{~Hz}, 1 \mathrm{H}), 6.71$ (dd, $J=8.8,2.5 \mathrm{~Hz}, 1 \mathrm{H}), 6.60(\mathrm{~d}, J=2.6 \mathrm{~Hz}, 1 \mathrm{H}), 6.07-6.02(\mathrm{~m}, 1 \mathrm{H})$, 4.04-3.95 (m, 1H), 3.79 (s, 3H), 2.95-2.75 (m, 2H), 2.61-2.54 (m, $1 \mathrm{H}), 2.52-2.39(\mathrm{~m}, 1 \mathrm{H}), 2.23-2.10(\mathrm{~m}, 2 \mathrm{H}), 2.02-1.94(\mathrm{~m}, 1 \mathrm{H})$, $1.54-1.49(\mathrm{~m}, 1 \mathrm{H}), 1.46-1.36(\mathrm{~m}, 1 \mathrm{H}) .{ }^{13} \mathrm{C}$ NMR $\left(101 \mathrm{MHz}, \mathrm{CDCl}_{3}\right): \delta$ 158.7, 138.0, 135.7, 127.1, 125.1, 115.5, 113.4, 112.9, 67.7, 55.4, $40.7,36.7,36.1,31.2,30.5$. HRMS: exact mass calculated for $[\mathrm{M}+\mathrm{H}]^{+}$ $\left(\mathrm{C}_{15} \mathrm{H}_{19} \mathrm{O}_{2}\right)$ requires $\mathrm{m} / z$ 231.1380, found $\mathrm{m} / \mathrm{z} 231.1378$. 